\title{
My Wellness as a Mobile App. Identifying Wellness Types among the Young Elderly
}

\author{
Anna Sell \\ Institute for Advanced \\ Management Systems Research \\ Åbo Akademi University \\ anna.sell@abo.fi
}

\author{
Camilla Walden \\ Institute for Advanced \\ Management Systems Research \\ Åbo Akademi University \\ pirkko.walden@abo.fi
}

\author{
Pirkko Walden \\ Institute for Advanced \\ Management Systems Research \\ Åbo Akademi University \\ camilla.walden@abo.fi
}

\begin{abstract}
Keeping ageing people healthy and active is of major importance both on an individual and societal level. We focus on a forgotten consumer group, 60-75 year olds - the young elderly - to uncover their wellness-related attitudes, habits and goals and explore prerequisites to introduce wellness-related mobile applications as a cost-effective solution to keeping the young elderly well longer. Preliminary results on a mixed-method study of young elderly and their use of mobile applications are presented.
\end{abstract}

\section{Introduction}

Aging of the population is a growing problem. The rising social and healthcare costs are creating a burden on the society that it cannot continue to bear. Aging is known for declines in cognitive, physical and social functions. Previous research has concentrated on enabling sustained activities of daily living despite physical and cognitive decline, in effect focusing on the portion of elderly already at the lower end of the functioning spectrum. Highly functioning elderly have been largely ignored, even though it is conceivable that health-maintaining routines and habits introduced at this stage could significantly postpone decline of functioning.

Aging is a worldwide phenomenon, where the numbers of old people outnumber the young. The mechanism behind aging is explained by decreasing mortality and diminishing fertility [46]. According to statistics, the share of people aged 60 or older increased from 9.2 percent in 1990 to 11.7 percent in 2013 [46]. The aging of the population is predicted to continue to grow; life expectancy at birth for both sexes globally was 71 years in 2013. The governments are ill prepared for the large structural changes that the aging will involve.

Within the age group of 60-74, impairments in functional ability are still quite rare. The problems start to increase at the age of 75 and beyond [15].
The need of preventative measures to maintain wellness among the ageing population is a highly topical issue. The impacts of aging cannot be stopped, but in many cases it can be slowed down.

Young elderly are defined as people within the age group of 60-75 years, separate from "senior citizens", people $65+$, "the ageing population" or other more broad terms referring to the older population as a homogeneous group. As mentioned before, functional impairments in this age group in Finland are still quite rare. The young elderly can be described as possibly having some age-related functional impairment, but are overall in reasonably good condition physically and mentally. Many of them have used computers and/or mobile technologies in their work careers and are thus not technological novices. We exclude from our definition individuals with severe illness, significant cognitive decline, in residential care and/or with need of everyday assistance, who need a different type of technological support or intervention. Our aim is to support continued wellness and everyday independence - keeping up functional ability, as opposed to meeting medical needs or treating illness. To implement early on new wellness routines that will enhance wellbeing while functional declines are still nonexistent or minimal, gives a wider range of possibilities, than to step in when functional declines are already visible. Mobile technology might offer cost-effective solutions to help keep young elderly well longer.

The "ageing population" is a broad and ill-defined segment of the population. The purpose of our study is to identify segments within the young elderly age group. We have formulated the following research questions: (1) Can we identify distinct segments regarding wellness attitudes and behavior within the young elderly age group? (2) Which wellness-related habits and goals do the young elderly commonly face? Our more overarching research question is: Do our results support employing mobile technologies 
among the young elderly to support wellnessenhancing habits and continued wellness?

In the following section we will give the literature background as well as central definitions used in the study. The third and fourth sections describe the research methods used for this study, how the data were collected and analyzed, as well as the findings of our study. In the last two sections we will discuss our results and provide some conclusions.

\section{Literature review 2.1. Defining wellness}

WHO (1948) describes health as "a state of complete physical, mental and social well-being and not merely the absence of disease or infirmity". Wellness is a construct with several dimensions and is often used as a holistic approach with the aim to improve a person's well-being. The use of antibiotics and vaccines reduced the mortality in infectious diseases. This lead to a shift, where chronic diseases and diseases related to lifestyle became more common. The concept of health underwent in the western world a change to a more holistic approach, including the mind, body and spirit [43]. Donatella, Snow and Wilcox (1999, p.7)[12] define wellness as "An active process of becoming aware and making choices to create a healthier lifestyle in all of life's dimensions". Myers, Sweeney and Wittmer (2000, p.252) [33] define wellness "as a way of life oriented towards optimal health and well-being, in which body, mind and spirit are integrated by the individual to live more fully within the human and natural community". Dunn defined wellness as "an integrated method of functioning which is oriented toward maximizing the potential of which the individual is capable"." It requires that the individual maintain a continuum of balance and purposeful direction within the environment where he is functioning" (Dunn 1961, p. 4-5) [13]. In his work he stresses that wellness is not merely a state, it is a continuum and it is made up different dimensions that overlap each other [14]. People should strive toward maximizing their potential of wellness. Myers et al. presented in their work, originally from 1998 a "wheel of wellness" that consisted of five dimensions; spirituality, self-regulation, work, friendship and love [33]. In Hettler's (1976) model, wellness is represented by six dimensions; physical, emotional, occupational, spiritual, intellectual and social [cf 33]. Some wellness models [2], [19],[38] include environment as one of the dimensions. The model of Renger et al[38] stems from the Canyon Ranche Life Enhancement Program. Greenberg [18] conceptualizes wellness in five dimensions; social, mental, emotional, spiritual, and physical. He defines wellness "as the integration of these components" and "high level wellness as the balance of these components" (Greenberg 1985,p.1) [18]. Wellness is in short about optimizing an individual's potential and concentrating on the strengths. It is a balance between the different dimensions that together form the core of wellness.

As pointed out, aging has been associated with stagnation. These declines are commonly related to cognitive, physical and social functions. The aging process is individual, known for its variation. The variation is partly explained by health behavior habits and psychosocial factors [1]. Biological aging is known for its plasticity. According to Aldwin et al. [1] exercise, diets low in saturated fats and high in antioxidants, social support, sense of control and emotional balance, will promote healthy aging. Surprisingly older people report often higher wellbeing than younger. The maintenance or improvement in well-being, despite the cognitive and physical aging is known as the "paradox of aging" [9].

The term "successful aging" has inspired a lot of researcher in gerontology, resulting in different models on how to define and measure life satisfaction [24]. Rowe and Kahn [41] point out that normal aging include a wide vast of variation. What is perceived as normal aging, can be divided into two different groups; those who age successfully and those that age the usual way. The key concept is to try to transit from usual aging into successful aging, by identifying the things that are vital for successful aging. The MacArthur model of successful aging [5],[39] is built on three premises, which contribute to successful aging; (i) low risk of disease and disease-related disability (ii) high cognitive and physical functioning and (iii) relations with others and productivity. In other words, high functioning is often equal with successful aging. Rowe and Kahn [39] specify that the model has been criticized for being too restrictive and has failed to take subjective factors into consideration. Also cultural factors have been dismissed. Strawbridge, Wallhagen and Cohen [45] found in their study that there was a discrepancy between investigator-rated and self-rated success in aging. A third of those who were aging successfully according to the criteria of Rowe and Khan [39], did not feel that they were aging successfully.

Health is often seen as one of the major factors in successful aging, however not all illnesses are preventable with a healthy lifestyle. The probability of chronicle illnesses and disabilities rises with age, thus making it important to be able to optimize and 
compensate. Baltes and Baltes [3] dynamic model "Selective Optimization with Compensation (SOC)" takes into account possible declines. According to the model, a healthy aging includes selection, optimization and compensation. Selection takes into account the limited resources; some activities or goals have to be avoided or restricted. A person needs to set and choose goals, since everything cannot be achieved. Optimization includes modeling others who are successful, obtaining means that are necessary and practicing the skills. Optimization can aim at developing already existing goals or to develop new ones. Compensation takes place when the means to attain goals are no longer in use.

To achieve a comprehensive view on the current understanding of wellness dimensions, we have compiled a synthesis based on Foster and Keller [16], Miller and Foster [28], Roscoe [cf 36] in table 1 below. It is important to acknowledge that wellness does not have an unequivocal definition, partly because it is a subjective experience. Therefore the conceptualizing of the dimensions vary, as well as the context in which the research has been done.

In our study we chose the following dimensions; physical, social, psychological, intellectual, occupational and spiritual. Physical wellness is an inevitable part of wellness, since physical exercise is known for the health giving effects. von Bondsdorff et al. (2009) found that people who had been physically active since midlife needed less end-of-life inpatient care [7]. Physical wellness was a natural choice as physical activities are easy to measure. Physical wellness is often equated to overall wellness, but to gain a more complete picture of wellness, one needs to consider other dimensions as well. In our overview of wellness dimensions (Table 1), social wellness is mentioned by all authors. Social activities are known to be related to lower death ratio..Social interaction with other people is an important part of wellbeing, and a source of concern, as elderly people report loneliness, or the fear of ending life alone as a major concern. Psychological wellness was chosen as a dimension, since for example depression is a major risk factor for wellness. Intellectual refers to the cognitive functioning and how to maintain it, a common concern among aging people. Occupational has to do with meaningful activities in the everyday life that enhances wellness. After retirement the young elderly need to create new occupational roles, in order to stay active and find life meaningful. Spiritual wellness has to do with the coherent understanding that life has a meaning. For some people the meaning can come from religion, but for those not religious, it is a feeling that life has a purpose. Other dimensions of wellness, such as cultural and climate, were excluded as they were less frequently mentioned in literature and/or difficult to measure.

\subsection{Mobile technology supporting wellness in the young elderly}

The elderly are identified as a historically underserved group of health consumers in research [30]. Also, the elderly are frequently dealt with as one coherent group in research, comprising of everyone above the age of 60 or 65 ; research specifically addressing the young elderly is scarce. Research on elderly people's use of technology has focused on adoption behavior, e.g. Deng [11], attitudes towards technology, e.g. Mitzner et al. [29] and evaluations of wellness-supporting applications or devices e.g. see Scandurra and Sjölinder [42], Mercer et al. (age 52-84) [27]. Several studies have investigated how mobile technologies can be employed to support the care of individuals with dementia-related diseases. The technology user in such studies is either the caregiver [26], [53] or the patient herself [47], [52]. The technology was utilized to e.g. aid communication, support reminiscence / recall and provide stimulation. These studies and mobile technologies are not as such applicable to the cognitively healthy and independent young elderly. On the other hand, any wellness-supporting mobile technologies directed at the general public, such as exercise-tracking applications and fitness bracelets, are an option to the young elderly as well as younger individuals. What is lacking is evidence that they could support maintained wellness among the young elderly and evaluations on whether the young elderly possess unique needs with regard to the technologies. Our research is aimed at this knowledge gap.

As technology users, a digital divide does seem to exist between younger and older adults, visible in lower usage of and experience with technology in general, as well as computers and the Internet [10] (sample aged 60-91 years). The divide widens when combined with a lower education level, i.e. older adults with a lower education level are less likely to use different technologies [10] [50]. On the other hand, it has been suggested that digital technology can protect older adults from the digital divide [22].

When examining initial adoption decisions, it has been found that subjective norm and perceived behavioral control are more important for older adults than younger [32]; subjective norm loses its significance with prolonged usage as domestication occurs. Heart and Kalderon [21] followed up on the 
study by Morris and Venkatesh [32] thirteen years later (sample aged 60-90+), finding that health status of the elderly person is a strong moderating factor regarding technology use; healthy older people are much more likely to be computer users. Nevertheless, age was still found to be a barrier to ICT use by Heart and Kalderon [21] and based on their findings the authors conclude that older adults are not yet ready to adopt health-related ICTs. Other studies have identified facilitating conditions to be of special importance for older adults decisions to adopt technology, such as Barnard et al. [4] (samples aged 58-78 and over 65, mean age 68) and Nägle and Schmidt [34] (sample aged 50-90). Marital status has also been found to be of importance; those living alone (and/or single, widowed, divorced etc.) are less likely to adopt technology. Finally, a positive and optimistic disposition has been found to be related to a higher likeliness to adopt technology [50].

In summary, research indicates that younger age, better health, higher education and not living alone are features associated with a higher likeliness to adopt and use technology.

Table 1 - Dimensions of wellness
Elderly people - the senior segment - are commonly seen as a richer aging population with good health but are also very often described as an undifferentiated, homogeneous group [17], [25]. However, the segment elderly people is also commonly identified by many researchers as highly heterogeneous [31],[44], [23],[8].

We share Borges Tiago et al (2016 p. 15) [8] opinion that "...the silver market, is not one large homogenous group...". Although their research context was travel and tourism we can see similarities to wellness services where people differ in attitudes and habits, thus we assume that the young elderly group consists of subgroups. Haustein [20] points out that the senior segment have different lifestyles than past generations and also higher expectations which points to the fact that the elderly are a heterogeneous group.

Discovering the young elderly's attitudes regarding wellness give us the possibilities to identify wellness types among the young elderly. There are different types of segmentation approaches. Our approach is a post-hoc descriptive method [51] through which segments are identified by forming groups of young elderly that are homogeneous along a set of measured

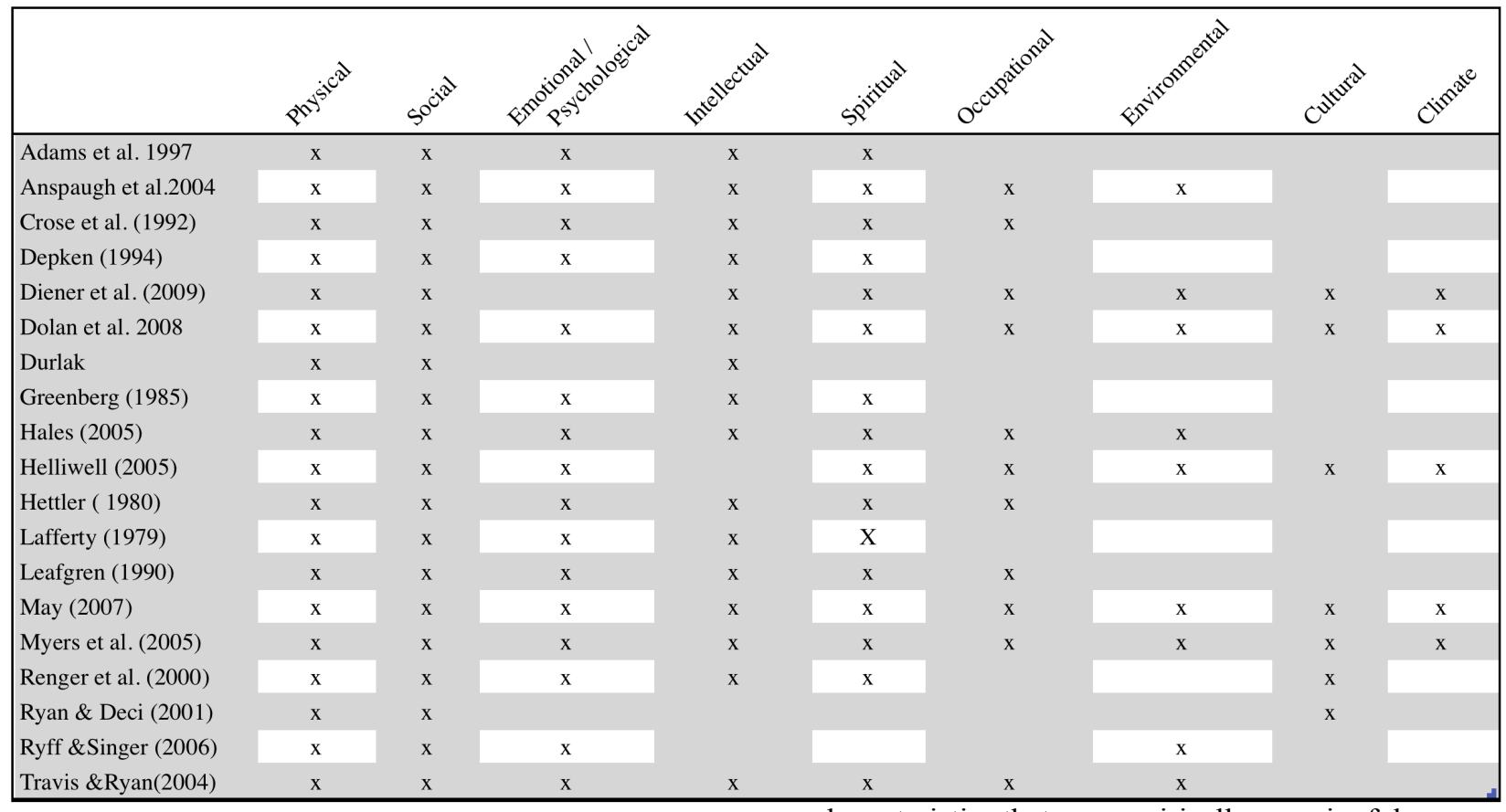

characteristics that are empirically meaningful.

\subsection{Segmentation}

Segmentation is about viewing a heterogeneous market as a number of smaller homogeneous markets. There are basically two different views of the senior segment, homogeneous and heterogeneous.

\section{Methodology - Mixed methods}

In our research we combine quantitative and qualitative research methods in order to develop a deep understanding of the young elderlys' everyday 
routines including wellness routines, the aspects that are affecting wellness and to provide data for segmenting this poorly known consumer group in order to uncover its potential to adopt mobile applications. In the study we use qualitative and quantitative methods sequentially, meaning that findings based on our focus group informed the survey which informed the interview study. Our purpose for conducting mixed methods research is for completeness which according to Venkatesh et al. (2013 p. 27] will “...provide a more holistic view of the phenomenon of interest than its qualitative and quantitative components will alone" [49].

At the first stage of data collection we formed an initial focus group comprising of five young elderly volunteers. At the second stage, a survey informed by literature studies and findings from the focus group was conducted targeting young elderly inhabitants of the Alland Islands. The study participants were recruited in cooperation with an association for retirees on the islands. At the third and final stage, we interviewed 34 people. The semi structured interviews conducted were informed by the findings from the survey. The study participants were again recruited in cooperation with an association for retirees. The interviews took place in Rusko and Lieto municipalities located close to Turku. The samples were chosen in such a way that we through these three studies gained a socioeconomically diverse picture of the young elderly. Participants to the interview study were members of a social democrat association, typically favored by persons with a working class background, whereas the focus group and survey participants were members of an association with a white-collar, middle-class affiliation.

\section{Data collection and results}

\subsection{Introductory focus group}

Our first research effort was to put together an initial focus group comprising of five young elderly volunteers, with the purpose of finding out their everyday routines including wellness routines. This group consisted of two females and three males, all having a high socioeconomic status. For measuring their physical activity we used the Physical Activity Scale for the Elderly (PASE). We also asked the focus group about their social, intellectual, mental, occupational and spiritual activities in order to track their wellness related routines during one week. Besides the demographic and socio-economic information we also collected information about their use of technology. The focus group interviews gave us a picture of the daily routines of the young elderly. In general we can conclude that the focus group participants were active, they took care of their wellness and they had experience in using mobile phones, tablet computers and mobile apps.

\subsection{Survey on young elderly}

At the second stage of data collection, a survey informed by literature studies and findings from the focus group was conducted targeting young elderly inhabitants of the Alland Islands. The study participants were recruited in cooperation with an association for retirees. An invitation to participate in the study through answering an online survey was mailed to 380 members. In all, 101 of the invitees replied to the questionnaire making the response rate $26.6 \%$ (one of the responses was removed from further analysis due to missing values). The purpose of the survey was both to investigate the potential among young elderly to adopt mobile applications, and to provide data for segmenting this poorly known consumer group. The insight gained from the survey was used as background for the subsequent interviews.

The participants were asked to answer questions regarding (i) demographic information, (ii) usage of mobile technologies (devices, services/apps), (iii) their intentions to adopt mobile applications as measured by UTAUT2 constructs, adapted from the original constructs in Venkatesh, Thong and $\mathrm{Xu}$ [48] and (iv) their physical and intellectual wellness.

Out of the 100 respondents, 76 indicated usage of mobile applications. When contrasted through an independent samples T-test, there were no significant differences between the user- and nonuser-groups regarding age, gender, income, education level or brand of mobile phone in use. The average age of the respondents is 69.6 years. $55 \%$ of the respondents are women. $42.6 \%$ of the respondents have university degrees. The most frequently owned smartphone brands are Nokia/Microsoft $(42.6 \%)$ and iPhone $(27.7 \%)$.

An initial principal component analysis with Varimax rotation was run on the set of eleven statements describing participants' physical and intellectual wellness, eliminating six variables with low factor loadings, low communalities or low measures of sampling adequacy. The variables were attitude statements graded on a 6-point forced attitude scale where $6=$ Completely agree and $1=$ Completely disagree. Variable loadings above 0.6 were seen to contribute to the factors. All included variables have communalities above 0.60 . A two-factor solution was 
determined to be most suitable, explaining about $74 \%$ of the variance. Cronbach's Alpha is 0.78 on the first factor and 0.734 on the second factor. Kaiser-MeyerOlkin Measure of Sampling Adequacy is 0.727 and Bartlett's Test of Sphericity gives 149.090, significance .000 . Variables, variable loadings and h2 values are presented in Table 2.

The first factor could briefly be described as referring to perceived physical health and attitude regarding future health. The second factor represents attitude towards intellectual challenges and their contribution towards the individual's wellbeing.

At the second stage of analysis, an initial hierarchical factor analysis was performed to identify the suitable number of segments, and subsequently kmeans clustering using Ward's method was performed as a post hoc analysis with the five wellness-related variables identified in the PCA. Cluster analysis results are presented in chapter 5 .

Table 2 - Factor loadings and communalities from PCA

\begin{tabular}{|c|c|c|c|}
\hline Variable & Factor 1 & Factor 2 & h2 \\
\hline $\begin{array}{l}\text { My resistance to physical illness } \\
\text { is good }\end{array}$ & 0,882 & & 0,783 \\
\hline $\begin{array}{l}\text { My phy sical health has been good } \\
\text { compared to people around me }\end{array}$ & 0,843 & & 0,753 \\
\hline $\begin{array}{l}\text { I expect my phy sical health to } \\
\text { remain good }\end{array}$ & 0,703 & & 0,6 \\
\hline $\begin{array}{l}\text { I feel drawn to activities demanding } \\
\text { reflection and reasoning }\end{array}$ & & 0,881 & 0,802 \\
\hline $\begin{array}{l}\text { Intellectual challenges are important } \\
\text { for my wellbeing }\end{array}$ & & 0,851 & 0,767 \\
\hline Variance explained (\%) & $53 \%$ & $21 \%$ & \\
\hline Cronbach's alpha & 0.78 & 0.734 & \\
\hline
\end{tabular}

\subsection{Interview study on 34 young elderly}

For the base of the interview we chose physical, social, intellectual, spiritual, emotional, economical and environmental dimensions of wellness, to gain a thorough understanding of the aspects that are affecting wellness. To find out about the wellness related habits and goals that young elderly commonly exhibits the everyday life of the young elderly, semi structured interviews were conducted. The interviews took place in Rusko and Lieto municipalities located close to Turku. Altogether 34 people were interviewed. Eight of them were men. The age range was between 60-77 years. Most of the participants had a low education and the mode in income was 10.000-20.000 euros per year.
The questions in the interviews were divided into following wellness areas: physical, social, intellectual, spiritual, psychological, occupational and environmental. All of the respondents were recruited through pensioner organizations, meaning that they were probably more active in general, than those that do not belong to any organization. The pensioner organizations are offering different kind of activities that the pensioners can participate in, such as gymnastics, concert trips and lectures.

\subsection{Results from segmentation}

The two distinct clusters acquired through $\mathrm{K}$ means procedure are summarized in Figure 1. The members of the first cluster can be described as feeling secure regarding their wellness. They are currently in good health and have an optimistic attitude regarding their future health. They acknowledge the importance of intellectual activities for their overall wellness, and show a positive attitude towards partaking in intellectually demanding pastimes. The members of the second cluster are at all points more negatively inclined. They rate their current physical health worse than members of the first cluster, and also have much lower expectations regarding their future health. They do not recognize that intellectual challenges would be beneficial for their wellbeing, but are not averse to partaking in such activities. We have named the clusters Secure wellness and Insecure wellness.

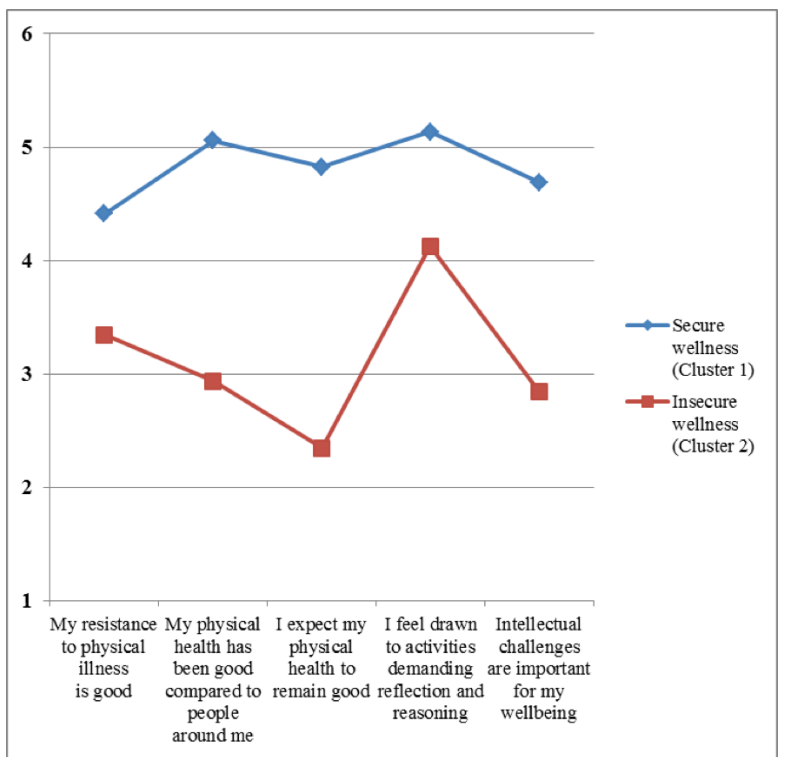

Figure 1- Attitudes by segment (scale $6=$ Agree completely, 1 = Disagree completely) 
When examined for differences in their demographic characteristics (age, gender, marital status, education, smartphone brand, yearly income) through Independent samples t-tests, the two clusters appear similar except on the account of yearly income; the Secure wellness group is significantly more well off $(\mathrm{M}=4.07, \mathrm{SE}=0.177)$ than the Insecure wellness group $(\mathrm{M}=3.03, \mathrm{SE}=0.182)$. This difference was significant $(t=4.101, \mathrm{p}<0.000)$.

Aside from the variables included in the cluster analysis, we have examined differences between the clusters regarding the other wellness-related statements evaluated in the questionnaire. Three significant differences emerge:

- I get sufficient intellectual stimulation in my everyday life (Secure wellness $\mathrm{M}=4.93$, $\mathrm{SE}=0.112$, Insecure wellness $\mathrm{M}=3.94$, $\mathrm{SE}=0.262 ; t(42.6)=3.48, \mathrm{p}<0.005))$

- The amount of information I have to process in my daily life is suitable for me (not too much, not too little) (Secure wellness $\mathrm{M}=4.33, \quad \mathrm{SE}=0.166$, Insecure wellness $\mathrm{M}=3.69, \mathrm{SE}=0.23 ; t(98)=2.203, \mathrm{p}<0.05))$

- My physical health has placed restrictions on me (Secure wellness $\mathrm{M}=2.37, \mathrm{SE}=0.198$, Insecure wellness $\mathrm{M}=3.38, \mathrm{SE}=0.310 ; t(98)=$ $-.81, \mathrm{p}<0.05)$ )

In other words, a more content attitude towards wellness in their everyday life was again seen in the Secure wellness group.

Finally, we determined whether the groups differ regarding their attitudes towards mobile applications and future potential to adopt possible wellnesssupporting mobile applications. Members of the Secure wellness cluster were significantly more likely to make use of mobile applications $(t(42.13)=-$ $2098, p<0.05)$. In all, a majority of both groups did utilize mobile applications; $82.4 \%$ of the Secure wellness group and $61.3 \%$ of the Insecure wellness group. The following significance analyses regarding attitudes towards mobile applications take into consideration only users of mobile applications $(\mathrm{N}=76)$. The attitude statements rated stem from the UTAUT2 constructs. There were no significant differences on most constructs, except the following:

- Using mobile applications help me carry out my tasks faster (Secure wellness $\mathrm{M}=3.96$, $\mathrm{SE}=0.173$, Insecure wellness $\mathrm{M}=3.1$, $\mathrm{SE}=0.315 ; t(74)=2.506, \mathrm{p}<0.05)$

- Using mobile applications increase my productivity (Secure wellness $\mathrm{M}=3.5$, $\mathrm{SE}=0.17$, Insecure wellness $\mathrm{M}=2.7, \mathrm{SE}$ $=0.341 ; t(74)=2.281, \mathrm{p}<0.05)$

- Using mobile applications is enjoyable (Secure wellness $\mathrm{M}=3.19, \quad \mathrm{SE}=0.186$,
Insecure wellness $\quad \mathrm{M}=2.35, \quad \mathrm{SE}=0.35$; $t(74)=2.257, \mathrm{p}<0.05)$

On these statements, the Insecure wellness group demonstrated a less favorable opinion. On the whole it is worth noting, that statements measuring respondents' performance expectancy, facilitating conditions, effort expectancy and behavioral intention regarding mobile applications are rated rather highly among the respondents in both groups, indicating possibilities to introduce mobile wellness applications successfully to consumers within this demographic group. The following statements were rated the highest (on a 5-point Likert scale):

- Mobile apps are useful in my life [M=4.32]

- I will continue to use mobile apps $[\mathrm{M}=4.19]$

- Using mobile apps help me carry out important tasks $[\mathrm{M}=4.08]$ (for a full list of statements see [6])

In free-text answers, respondents gave examples of mobile applications they make use of. Weather services, news services, messaging services and map applications were frequently mentioned.

\subsection{Results from interviews}

The most common obstacles for participating in different activities were related to psychological factors such as "What will others think of me", "What would I do there" (even when the activity in itself is meaningful) and the doubts of "How to act in social situations". Also other aspects such as alcohol problems, loneliness (no one to go with) and a controlling partner were frequently mentioned.

The most commonly mentioned activities to enhance wellness were related to the physical dimension (exercise and healthy diet), social dimension (close social relationships), intellectual dimension (learning new things), occupational dimension (meaningful activities) and economical (economical security). Most of the participant had a smart phone in their use or were thinking of buying a smart phone. Most of the participant were also used to using a computer or/and a tablet. However, all mentioned they used their phone more as a tool than a lifestyle accessory. None of the participants mentioned that they would be addicted to using a phone. A few said they had limited their time spent on the computer, since otherwise they would get nothing else done during the day.

Almost all participants mentioned that they exercise more now, than while they were still working. This was mainly related to the fact, that they had more time now to do things, than while working. Physical activity was commonly related to the social dimension; many mentioned social contacts 
working as a motivator in taking part in physical activities. This fact is supported by previous research. Many women also mentioned doing handicrafts as both as a meaningful activity as well as a therapeutically one. In the intellectual wellness part, a clear worry for possible cognitive decline was discussed. Some of the participants had created daily activities and strategies to enhance memory functions. However this could be one aspect where digital solutions could come handy.

Incidental exercise was commonly mentioned. Especially during the summer, incidental exercise was reported to be higher. Many of the devices measuring physical activity do not reliably measure this sort of exercise. In the focus group the Fitbit Charge and Polar Loop only measured steps/stairs climbed and the time during which the participant was active, but fail to meet the needs of measuring incidental exercise. Especially men reported fishing, hunting and doing land clearing work. Steps measured during more demanding incidental exercise does not give a correct picture of how straining the activity was.

\section{Discussion and conclusions}

We have identified two different clusters, Secure wellness and Insecure wellness. The members of the first cluster we described as feeling secure regarding their wellness. The members of the second cluster are more negatively inclined. When we compare the two clusters in terms of demographic characteristics we find differences only in yearly income. The Secure wellness cluster is significantly more well off than the Insecure wellness cluster. When we compared those variables not included in the cluster analysis we found three significant differences, which point to the fact that the Secure wellness cluster has a more content attitude towards wellness in their everyday life.

The members of the clusters also differ regarding attitudes towards mobile applications and future use. Members of the Secure wellness cluster were significantly more likely to make use of mobile applications. This is in line with previous research indicating that better health in elderly is associated with higher adoption and use of technology. However, a majority of both clusters did utilize mobile applications. Introducing wellness-supporting mobile applications to the young elderly seems possible; the interviewed and surveyed young elderly reported using smart phones to a high degree and were also used to computers. This was true both among the young elderly survey respondents, being a group with higher overall income and education, and the interview respondents, a group with a low mean income and education.

The Insecure wellness group would likely need more individualized support, both due to their more risky wellness profile and their somewhat higher reluctance to adopt and use mobile technologies. They report their current health and health outlook to be worse than in the Secure wellness group. The Secure wellness group would likely be served well enough with a more standard service, and more resources could be vested into tailoring support for the Insecure wellness group. Further analysis is needed to pinpoint which wellness dimensions would be most important to target in order to increase wellness in the Insecure wellness group.

The social dimension of wellness is important, as it is mentioned as an enabler for participating in physical activities, and on the other hand visible as obstacles for participating in activities (uncertainty of how to behave in social situations, having no one to go with). Furthermore, it is known that loneliness is increasingly common with advancing age and a risk factor. Social support through mobile technology might alleviate social obstacles, e.g. through tailored social networking.

The young elderly are commonly worried for impending cognitive decline, i.e. their intellectual wellness. Memory training and enhancing activities are easy to deliver through mobile applications and can be tailored to individual needs.

The next step of our research will be a systematic analysis of the interviews which we have carried out during year 2016. For this purpose we will use a qualitative data analysis software, NVivo.

\section{References}

[1] Aldwin, C.M., Spiro, A., and C.L. Park, Health, behavior, and optimal aging; A lifespan developmental perspective. In J.Birren \& K.W.Schaie (EDS.), Handbook of the psychology of aging, sixth edition. (pp.85-104). San Diego:Academic Press., 2006.

[2] Anspaugh,D., Hamrick,M., and F. Rosato, (2004).Wellness: Concepts and Applications 6th ed. Boston: McGrawHill.

[3] Baltes, P. B., and M.M. Baltes, Psychological perspectives on successful aging: The model of selective optimization with compensation. In P. B. Baltes \& M. M. Baltes. (Eds.), Successful aging: Perspectives from the behavioral sciences, pp. 1-34, New York: Cambridge University Press, 1990. 
[4] Barnard, Y., Bradley, M.D., Hogdson, F., and A.D. Lloyd, "Learning to use new technologies by older adults: Perceived difficulties, experimentation behaviour and usability", Computers in Human Behavior (2013), 29:4, pp 1715-1724.

[5] Berkman, L. F., Seeman, T. E., Albert, M., Blazer, D., Kahn, R., Mohs, R., ... \& Nesselroade, J., "High, usual and impaired functioning in community-dwelling older men and women: findings from the MacArthur Foundation Research Network on Successful Aging.", Journal of clinical epidemiology, 46(10), 1993, pp 1129-1140.

[6] Carlsson, C., and Walden, P. "Digital wellness services for 'young elderly' - a missed opportunity for mobile services". Journal of Theoretical and Applied Electronic Commerce Research, 11(3), 2016, pp 20-34.

[7] von Bonsdorff, M.B., Rantanen,T., Leinonen,R.,Kujla,U.M.,Törmäkangas,T., Mänty,M., and E. Heikkinen,"Physical Activity History and End-of-Life Hospital and Long-Term Care (2009) J Gerontol A Biol Sci Med Sci 64 A (7): 778-784. doi:10.10937gerona/glp029.

[8] Borges Tiago, Maria Teresa Pinheiro Melo João Pedro de Almeida Couto, Flávio Gomes Borges Tiago, Sandra Micaela Costa Dias Faria, "Baby boomers turning grey: European profiles", Tourism Management, Vol. 54 (2016) pp.13-22.

[9] Carstensen, L. L., Mikels, J. A., and M. Mather, Aging and the intersection of cognition, motivation and emotion. In J. Birren, \& K. W. Schaie (Eds.), Handbook of the Psychology of Aging (6th ed., pp.343-362). San Diego, CA: Academic Press, 2006.

[10] Czaja, S.J., Charness, N., Fisk, A.D., Hertzog, C., Nair, S.N., Rogers, W.A. and J. Sharit, "Factors Predicting the Use of Technology: Findings From the Center for Research and Education on Aging and Technology Enhancement (CREATE)", Psychology and Aging (2006), 21:2, pp 333-352.

[11] Deng, Z., Mo, X. and S. Liu, "Comparison of the middle-aged and older users' adoption of mobile health services in China", International Journal of Medical Informatics, 83(2014), pp 210-224.

[12] Donatelle, R., Snow, C., and A. Wilcox, Wellness $2^{\text {nd }}$ ed, Wadsworth Publishing Company, Belmont, CA, 1999.

[13] Dunn, H. L., (1961 )High Level Wellness, Beatty Press: Arlington, VA.

[14] Dunn, H.L., "High-Level Wellness for Man and Society", American Journal of Public Health and the Nations Health, 1959, 49(6), pp 786-792.
[15] Findicator.fi, Statistics Finland. 2014. [ONLINE] Available at: http://www.findikaattori.fi/en. [Accessed 14 June 2016].

[16] Foster, L.T,. Keller, C. P.,(2007) British Columbia atlas of wellness .Western Geographical Press, Department of Geography, University of Victoria.

[17] Goulding, C., "An exploratory study of age related vicarious nostalgia and aesthetic consumption", in Broniarczyk, S. and Nakamoto, K. (Eds), Advances in Consumer Research, Vol. 29, (2002), Association for Consumer Research, Provo, UT, pp. 542-6.

[18] Greenberg, J. S.(1985).Health and Wellness: A conceptual differentiation. Journal of School Health,55,403-406.

[19] Hales, D., An Invitation to Health, 11th ed. Belmont, CA: Thomson \& Wadsworth, 2005.

[20] Haustein, S., "Mobility Behavior of the Elderly: An Attitude-based Segmentation Approach for a Heterogeneous Target Market", Transportation, Vol 39:6, 2011, pp 1079-1103.

[21] Heart, T., and E. Kalderon, "Older adults: Are they ready to adopt health-related ICT?", International Journal of Medical Informatics (2013), 82:11, pp e209-e231.

[22] Hill, R., L.R. Betts, and S.E. Gardner, "Older adults' experiences and perceptions of digital technology: (Dis)empowerment, wellbeing, and inclusion", Computers in Human Behavior 48 (2015), pp 415-423.

[23] Jang, S.S. and C.-M.E. Wu, "Seniors' travel motivation and the influential factors: an examination of Taiwanese seniors", Tourism Management, 27 (2) (2006), pp. 306-316

[24] Katz, S. and T. Calasanti, (2014) Critical Perspectives on Successful Aging: Does It "Appeal More Than It Illuminates"? The Gerontologist. doi: 10.1093/geront/gnu027, First published online: April 18, 2014.

[25] Lee, L., "Love those boomers", Business Week, October 24, (2005), pp. 94-102.

[26] Maiden, N., D'Souza, S., Jones, S., Müller, L., Pannese, L., Pitts, K., Prilla, M., Pudney, K., Rose, M., Turner, I. and Zachos, K., 2013. Computing technologies for reflective, creative care of people with dementia. Communications of the ACM, 56(11), pp.60-67.

[27] Mercer, K., Giangregorio, L., Schneider, E., Chilana, P., Li, M., \& Grindrod, K. (2016). Acceptance of commercially available wearable activity trackers among 
adults aged over 50 and with chronic illness: a mixedmethods evaluation. JMIR mHealth and uHealth, 4(1).

[28] Miller, G. and L. Foster, Critical Synthesis of Wellness Literature (2010) University of Victoria. Faculty of Human and Social Development and Department of Geography.

[29] Mitzner, T.L. et al, "Older adults talk technology: Technology usage and attitudes", Computers in Human Behavior (2010), 26:6, pp 1710-1721.

[30] Montague, E., and J. Perchonok, "Health and Wellness Technology Use by Historically Underserved Health Consumers: Systematic Review", Journal of Medical Internet Research (2012), 14:3, e78.

[31] Morgan, C.M. and Levy, D.J., "The boomer attitude", American Demographics, Vol. 24 No. 9, (2002), pp. 42-6.

[32] Morris, M.G., and V. Venkatesh, "Age Differences in Technology Adoption Decisions: Implications for a Changing Work Force", Personnel Psychology (2000), 53:2, pp 375-403.

[33] Myers, J. E., Sweeney, T. J. and J.M. Witmer, "The Wheel of Wellness Counseling for Wellness: A Holistic Model for Treatment Planning", Journal of Counseling \& Development, 2000, 78(3), 251.

[34] Nägle, S., and L. Schmidt, "Computer acceptance of older adults”, Work (2012) 41, pp 3541-3548.

[36] Reis, H. T., Sheldon, K. M., Gable, S. L., Roscoe, J., and R.M. Ryan, "Daily well-being: The role of autonomy, competence, and relatedness.", Personality and Social Psychology Bulletin, Vol. 26 (2000), pp., 419-435.

[38] Renger, R. F., Midyett, S. J., Mas, F. G., Erin, T. E., McDermott ,H. M., Papenfuss, R .L., Eichling, P.S., Baker, D. H., Johnson, K. A. and M.J. Hewitt, (2000). Optimal Living Profile: And inventory to assess health and wellness. American Journal of Health Promotion, 24 (6) 403-412.

[39] Rowe, J. W., and R.L. Kahn, "Human Aging: Usual and Successful”, Science, 237, (1987), pp-143-149.

[40] Rowe, J.W., and R.L. Kahn, Successful Aging. New York: Pantheon/Random House, 1998.

[41] Rowe, J. W., and R.L. Kahn, "Successful Aging 2.0: Conceptual Expansions for the 21st Century", The Journals of Gerontology Series B: Psychological Sciences and Social Sciences, gbv025, 2015, http://doi.org/10.1093/geronb/gbv025

[42] Scandurra I and M. Sjölinder, "Participatory Design With Seniors: Design of Future Services and Iterative
Refinements of Interactive eHealth Services for Old Citizens", Medicine 2.0 2013;2(2):e12

[43] Seaward, B.L., Managing Stress: Principles and Strategies for Health and Well-being, M.A. Jones and Bartlett, Boston, 2002.

[44] Sellick, M.C., "Discovery, connection, nostalgia: key travel motives within the senior market", Journal of Travel \& Tourism Marketing, 17 (1) (2004), pp. 55-71.

[45] Strawbridge, W. J., Wallhagen, M. I., and R.D. Cohen, Successful aging and well-being: self-rated compared with Rowe and Kahn. The Gerontologist, 2002, 42(6), pp 727733.

[46] United Nations Department of Economic and Social Affairs, Population ageing and sustainable development, no. 4, 2014, available at: http://www.un.org./en/development/desa/population/publications/pdf/popfacts/Popfacts

[47] Upton, D., Upton, P., Jones, T., Jutlla, K., Brooker, D. and Grove, H., 2011. Evaluation of the impact of touch screen technology on people with dementia and their carers within care home settings. UK: University of Worcester.

[48] Venkatesh, V., Thong, J.Y., and X. Xu, "Consumer Acceptance and Use of Information Technology: Extending the Unified Theory of Acceptance and Use of Technology", MIS Quarterly, 36:1, pp. 273-315.

[49] Venkatesh, V., Brown, S.A. and H. Bala, "Bridging the Qualitative-Quantitative Divide: Guidelines for Conducting Mixed methods Research in Information Systems", MIS Quarterly, 37:1, pp. 21-54.[

50] Vroman, K.G., Arthanat, S., and C. Lysack, "Who over 65 is Online?" Older adults' Dispositions toward Information Communication Technology", Computers in Human Behavior 43 (2015), pp 156-166.

[51] Wedel, M. and W. Kamakura, Market Segmentation:Conceptual and Methodological Foundations. Norwell, Massachusetts, Kluwer Academic Publisher, 2001.

[52] Yamagata, C., Coppola, J.F., Kowtko, M. and Joyce, S., 2013, May. Mobile app development and usability research to help dementia and Alzheimer patients. In Systems, Applications and Technology Conference (LISAT), 2013 IEEE Long Island (pp. 1-6). IEEE.

[53] Zachos, K., Maiden, N., Pitts, K., Jones, S., Turner, I., Rose, M., Pudney, K. and MacManus, J., 2013, June. A software app to support creativity in dementia care. In Proceedings of the 9th ACM Conference on Creativity \& Cognition (pp. 124-133). ACM. 
